\title{
Lateral inhibition and the Wundt-Hering illusion
}

STANLEY COREN, The New School for Social Research, New York, N.Y. 10011

Lateral inhibition has been suggested as the mechanism that is responsible for many of the visual geometric illusions. It operates through the mutual inhibition and displacement of spatially adjacent contours. Using a modified Wundt-Hering illusion, it was shown that, even in the absence of such spatially adjacent contours, the expected illusion still occurs. This result casts some doubt on the adequacy of the lateral inhibitory explanation of geometric illusions.

Recently, Békésy (1967) and Ganz (1966) have suggested that many of the classical geometric illusions are produced by the operation of lateral inhibitory retinal processes. Ganz, for instance, assumes that the apparent location of a contour is determined by the maximum of the distribution of neural excitation that results from imaging a contour on the retina. When two contours are spatially adjacent, they interact, such that the peaks of excitation distributions are shifted away from each other. This shift is due to the fact that the parts of the distributions that are closest to each other are most strongly inhibited. One result of such a process is the apparent opening out of acute angles. Ganz proposes such angular spreadings could be made to account for such illusions as the Zollner, Wundt, Hering, Poggendorff, and Müller-Lyer.

Since this theory is based upon the apparent opening out of acute angles due to the operation of lateral inhibition, elimination of such acute angles should result in the disappearance of the illusions. This then allows us to test this formulation directly.

\section{STIMULI}

A modified Wundt-Hering illusion served as the basic stimulus. Figure $1 \mathrm{~A}$ shows the the test lines by means of a variable prism through which he viewed the display. The variable prism was mounted in front of S's right eye, along with a Wratten No. 55 (green) filter that was used to eliminate chromatic fringes. The number of prism diopters set by $S$ could be read directly from a scale attached to the prism mount.

The Ss were eight student volunteers recruited from The New School for Social Research. All had 20/20 vision or better and were naive as to the purpose of the experiment.

\section{PROCEDURE}

The Ss were first shown how, by varying the strength of the prism, they could vary the apparent curvature of a line. All Ss then made two practice matches, setting a physically curved line until it appeared to illusion in a continuous line form where the operation of lateral inhibition can easily account for the apparent upward bowing of the horizontal line. Figure 1B shows a modified version of the stimulus where all of the vertices have been replaced by dots in a horizontal straight array. In this configuration, since no acute angles are present, no bowing of the line should appear if the illusion depends solely upon lateral inhibitory processes.

These stimuli were prepared on white paper, $20 \times 28 \mathrm{~cm}$, using black ink lines, $1 \mathrm{~mm}$ wide

Two control stimuli were also prepared; one was a horizontal straight line and the other a horizontal straight line composed of dots with the same spacing as the dots in Fig. 1B. These stimuli provide a base line against which the illusion magnitudes may be assessed. A physically bowed line served as a practice stimulus.

\section{APPARATUS AND SUBJECTS}

The stimuli were individually displayed $40 \mathrm{~cm}$ from $S$ on a white background. S's head was held immobile by means of a chin rest. $S$ could vary the apparent curvature of
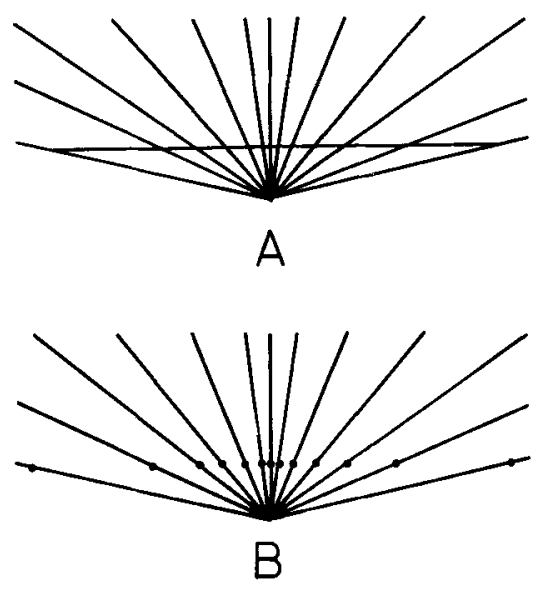

Figure 1 be straight. After this, the two illusion stimuli and the two control stimuli were presented in random order. Each $\mathrm{S}$ was instructed to set the prism until the test line appeared to be straight. He made two settings on each figure.

RESULTS AND DISCUSSION

The measure of the illusion magnitude is obtained by subtracting the mean settings of apparently straight for the appropriate I control figure (the continuous horizontal line, or the horizontal row of dots) from the settings of apparently straight for the corresponding illusion figure.

We find that the standard line form of the illusion yields a mean curvature of 6.06 prism diopters, which is significantly different from zero $(\mathrm{t}=3.11,7 \mathrm{df}$, $p<0.02)$. The alternate form of the illusion, which contains no acute angles, also produces a significant amount of illusory curvature in the predicted direction, amounting to a mean of 10.6 diopters $(t=4.46,7 \mathrm{df}, p<0.01)$. If lateral inhibition is completely responsible for the occurrence of the illusion, we would expect no apparent curvature in this alternate form. It is interesting to note that the magnitude of the illusion in the alternate form is actually slightly greater than that for the normal configuration, although this difference is not significant $(t=1.55,7 \mathrm{df})$. The existence of a significant illusion thus suggests that lateral inhibition is not the primary cause of the apparent curvature of the line in the Wundt-Hering illusion. The question of whether or not lateral inhibition may play a role in the formation of other classical geometric illusions, such as the Zollner, Poggendorf, or Muller-Lyer, is still, of course, unsettled.

\section{REFERENCES}

von BÉKÉSY, G. Sensory inhibition. Princeton, N.J: Princeton University Press, 1967.

GANZ, L. Mechanism of the figural after effects. Psychological Review, 1966, 73, 128-150. 